\title{
Macular optical coherence tomography findings following blunt ocular trauma
}

\author{
This article was published in the following Dove Press journal: \\ Clinical Ophthalmology \\ 19 May 2014 \\ Number of times this article has been viewed
}

\section{Dilys Oladiwura' \\ Lik Thai Lim' \\ Elliott Yann Ah-kee ${ }^{2}$ James Angus Scott ${ }^{3}$}

'Tennent Institute of Ophthalmology, Gartnavel General Hospital (NHS Greater Glasgow and Clyde Trust), Glasgow, UK; ${ }^{3}$ Falkirk Community Hospital (Forth Valley NHS Trust), Falkirk, UK Glasgow, UK; ${ }^{2}$ University of Glasgow,
Correspondence: Elliott Yann Ah-kee University of Glasgow School of Medicine, University Avenue, Glasgow, GI 2 8QQ, UK

Email elliottahkee@gmail.com
Abstract: This case report describes the optical coherence tomography (OCT) results of Berlin's edema in a male subject following blunt ocular trauma from a soccer ball. A 27 -year-old male presented with blurred vision in his left eye following blunt trauma. On admission, he underwent a complete eye examination and an OCT of the macula. Fundoscopy revealed commotio retinae, observed as an abnormal cream-colored discoloration of the fovea. The OCT showed outer photoreceptor segment disruption, retinal pigment epithelium inter-digitation, and intra-retinal edema of the outer nuclear layer. Following initial management, a repeat OCT after 3 months showed near complete resolution. OCT can be a useful adjunct for monitoring the progress of Berlin's edema secondary to blunt ocular trauma because Berlin's edema may present similarly clinically to other ocular trauma, but can affect different layers of the retina depending on the type of injury to the eye.

Keywords: Berlin's edema, commotio retinae, optical coherence tomography, OCT, ocular trauma

\section{Introduction}

Optical coherence tomography (OCT) is a valuable tool for imaging macular trauma. It provides detailed images of the anatomical structures of the eye for diagnostic purposes and enables the monitoring of various macular and chorioretinal pathological changes, particularly in acute traumatic maculopathy. This case report describes the OCT findings of Berlin's edema at diagnosis and follow-up in a male patient with acute traumatic maculopathy.

\section{Case report}

A 27-year-old Caucasian male presented with a 24-hour history of blurred vision in his left eye following blunt trauma caused by the high velocity impact of a soccer ball. No other injuries were noted. He had unremarkable medical and ocular histories. On presentation, best-corrected visual acuity (BCVA) was 6/5 for the right eye and $6 / 18$ for the left. Clinical examination of the right eye was unremarkable. Examination of the left eye revealed a microhyphema and an inferotemporal angle recession; intraocular pressure (IOP) was $40 \mathrm{mmHg}$. Fundoscopy revealed superotemporal peripheral commotio retinae and an abnormal cream-colored linear area of the fovea (Figure 1A). There was no pigment in the vitreous, no retinal tear or detachment, and the posterior vitreous was intact. OCT of the left macula showed an acute traumatic maculopathy consisting of a disruption of the outer photoreceptor segment, and retinal pigment epithelium inter-digitation associated with intra-retinal edema of the outer nuclear layer. A disruption of the inner and outer segments adjacent to the fovea was also observed (Figure 1B). Central foveal thickness at time of presentation measured $255 \mu \mathrm{m}$. The patient was advised to avoid strenuous activity. 

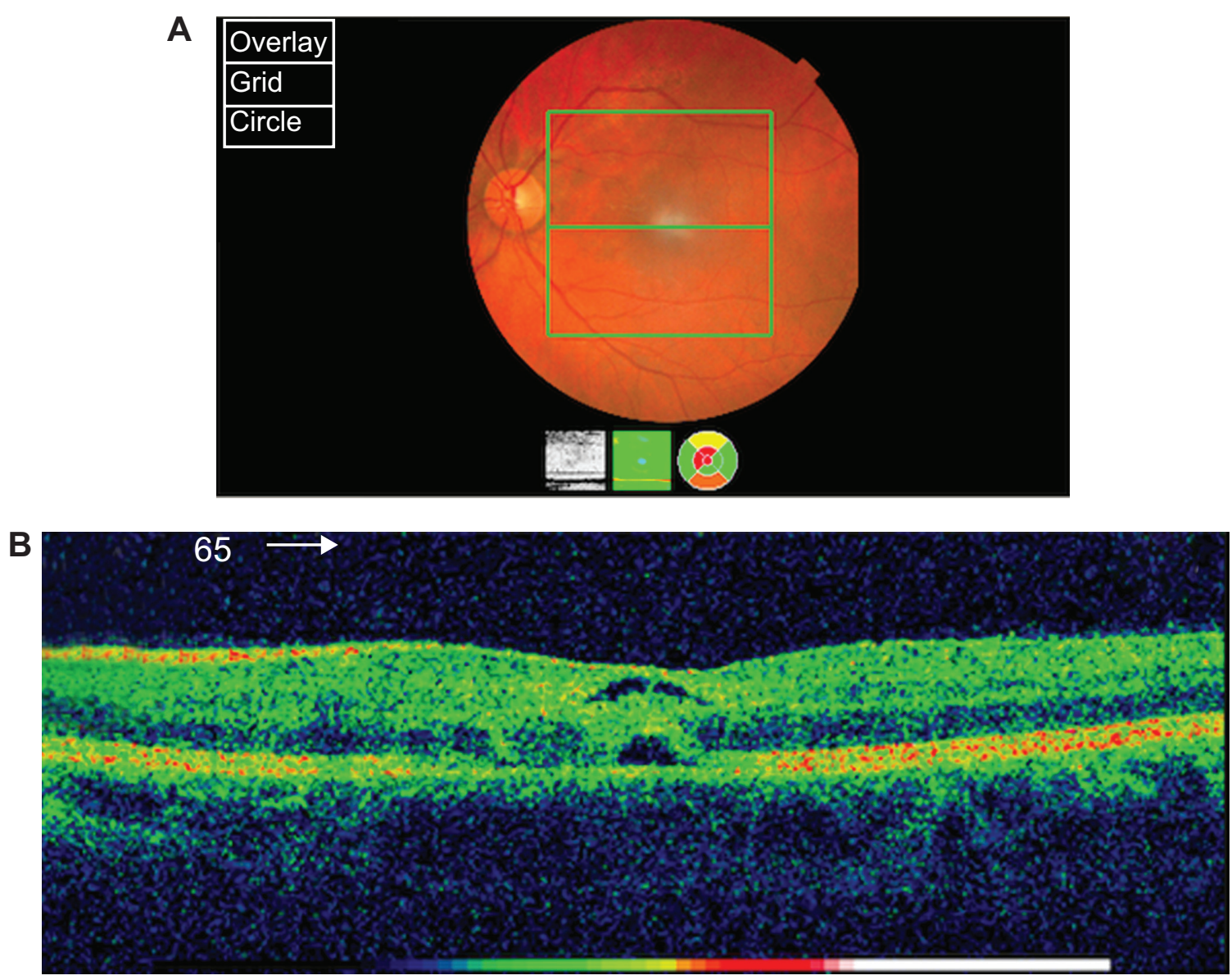

Figure I Fundoscopy and OCT at presentation.

Notes: (A) Fundoscopy at presentation showing superotemporal commotio retinae and an abnormal cream foveal discoloration. (B) The OCT of left macula at presentation shows outer photoreceptor segment disruption, RPE inter-digitation with some outer and inner segment foveal disruption, and intra-retinal edema at the outer nuclear layer.

Abbreviations: OCT, optical coherence tomography.

He was prescribed prednisolone eye drops $1 \%$ four times daily and timolol $0.5 \%$ twice daily to the left eye, as well as slow release oral acetazolamide $250 \mathrm{mg}$ twice daily. The left eye was examined daily due to the microhyphema. At day 3 post injury, left BCVA was 6/12 with an IOP of $15 \mathrm{mmHg}$. At the end of week 1, anti-glaucoma treatments were discontinued; however, by week 2 , they had to be resumed because IOP had increased to $35 \mathrm{mmHg}$. A week later, oral acetazolamide was replaced with topical brinzolamide to optimize IOP control and Travatan ${ }^{\circledR}$ (Alcon Laboratories Inc., Forth Worth, TX, USA) was added to the regimen. IOP in the left eye eventually stabilized at $13 \mathrm{mmHg}$.

A repeat fundoscopy and OCT of the left macula at 3 months post injury revealed almost complete resolution of the edema, with a small discontinuity in the inner and outer segments adjacent to the fovea (Figures 2A, 2B). A central foveal thickness of $133 \mu \mathrm{m}$ was observed and BCVA had improved to 6/7.5.

\section{Discussion}

OCT is a powerful non-invasive tool for evaluating macular trauma. Compared to other imaging methods, it is comfortable for the patient in a trauma setting because it is non-invasive. High-depth resolution $(10 \mu \mathrm{m})$ cross-sectional tomographs of the ocular tissue provided the clinician a detailed view of the anatomical structures of the eye. ${ }^{1}$ The characteristic feature of Berlin's edema is retinal opacification. It was first described as commotio retinae by Berlin in 1873 in a case of blunt trauma to the globe. ${ }^{2}$ Previous studies have suggested that opacity is the result of damage to the retinal pigment epithelium and photoreceptor outer segments. Loss of vision seems to be the result of permanent loss of these photoreceptors. ${ }^{3,4}$ Based on histopathologic findings from human cadaver eyes, Mansour et $\mathrm{al}^{5}$ showed that the major site of injury in commotio retinae is likely at the photoreceptor outer segmented-retinal pigment epithelium junction. 

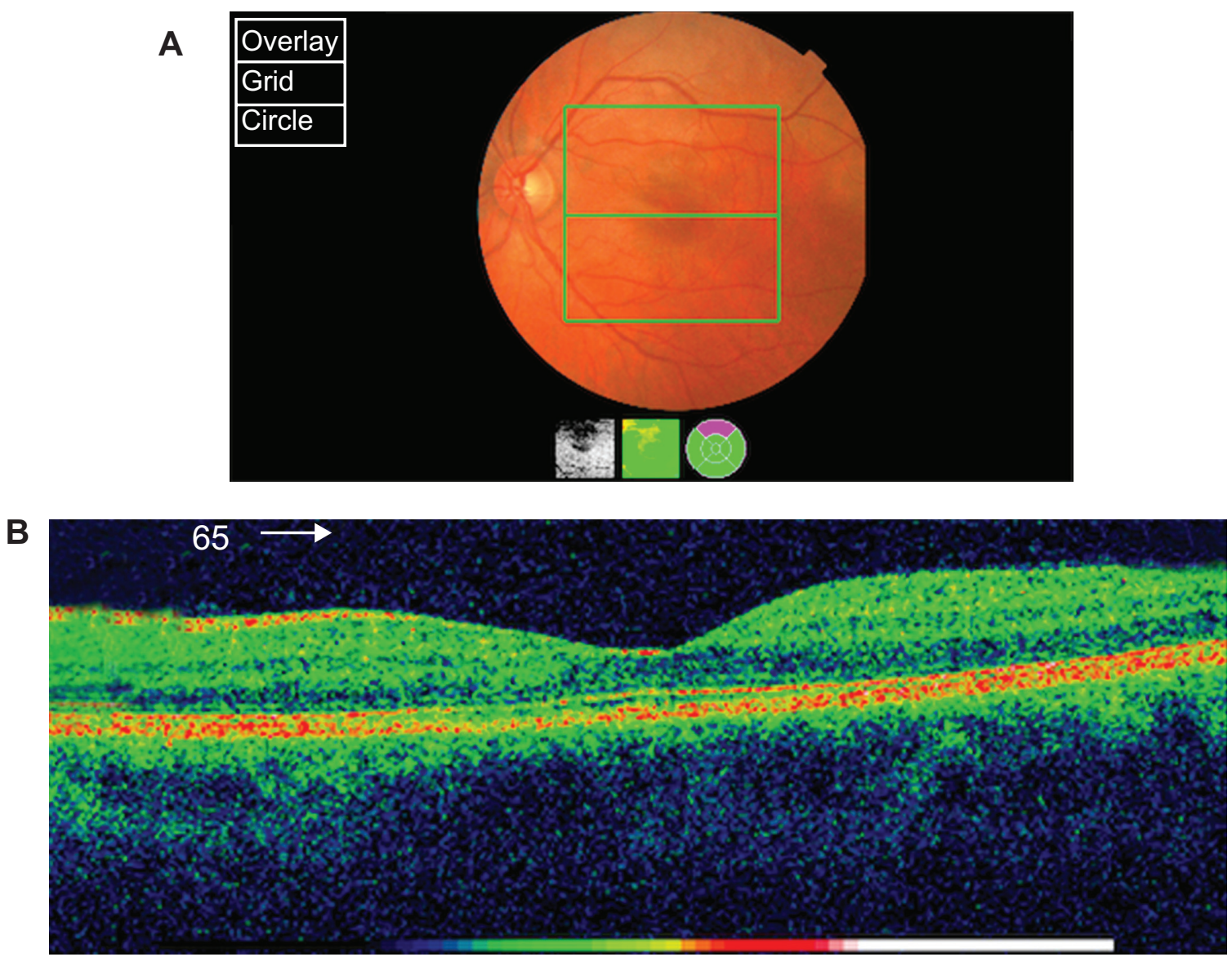

Figure 2 Fundoscopy and OCT after 3 months.

Notes: (A) Fundoscopy after 3 months suggests almost complete resolution of the retinal layers. (B) OCT findings after 3 months suggest almost complete resolution of the retinal layers edema with a small discontinuity in the inner and outer segments adjacent to the fovea.

Abbreviations: OCT, optical coherence tomography.

OCT has recently been used to analyze the pathophysiology of commotio retinae, confirming previous histological findings of an abnormal outer segment layer of the retina. Studies of OCT results by Meyer et al, ${ }^{6}$ Sony et al, ${ }^{7}$ and Ismail et $\mathrm{al}^{8}$ that examined commotio retinae showed increased reflectivity of the photoreceptor outer segment of the eye.

The current case describes the OCT findings of Berlin's edema subsequent to blunt trauma. Clinical signs resolved at 3 months post injury, with a corresponding improvement in BCVA. The mechanism of injury was presumed to be blunt force trauma transmitted to the retina resulting in rapid deceleration of ocular tissues.

To date, there have been no studies describing Berlin's edema secondary to blunt trauma from a soccer ball. Previous reports have described OCT results of Berlin's edema from different types of injury, which improved over time. For instance, Pham et $\mathrm{al}^{9}$ reported two cases of acute traumatic maculopathy following a motor vehicle accident. OCT findings from these cases showed outer retinal thickening, a low signal triangular area below the foveal pit, and increased central foveal thickness. Repeat OCT showed a resolution of foveal changes and a decrease in central foveal thickness. In addition, OCT findings from a case report by El Matri et $\mathrm{al}^{10}$ revealed thickening of the outer retinal structures and increased reflectivity in the outer photoreceptor segments with preservation of inner retinal architecture. However, the repeat OCT showed regression of foveal thinning, hyper-reflectivity at the outer photoreceptor segments, and an increase in central foveal thickness. Itakura and Kishi ${ }^{11}$ reported spectral domain optical coherence tomography (SD-OCT) findings of the healing phase in three cases of commotio retinae in the posterior pole. SD-OCT showed increased reflectivity of the line at the junction between the photoreceptor inner and outer segments. The repeat SD-OCT revealed resolution of the neurosensory retinal edema and restoration of the photoreceptor architecture, consistent with improved BCVA.

The current case presents a series of OCT findings that showed improvement over time. Initial OCT findings revealed outer photoreceptor segment disruption, retinal pigment epithelium inter-digitation with some outer and 
inner segment foveal disruption, and intra-retinal edema in the outer nuclear layer. Follow-up OCT showed almost complete resolution. It appears that although these cases resulted in the same clinical outcomes, Berlin's edema, the layers of the retina affected were slightly different, possibly due to different mechanisms of injury. ${ }^{6-11}$ Additional studies are required to investigate this possible association.

Further to the few case reports available, the current case report adds to the literature on variations in retinal findings secondary to blunt eye trauma observed on OCT, possibly due to the nature and severity of the trauma. To summarize, OCT can be a useful adjunct for monitoring the progress of Berlin's edema secondary to blunt ocular trauma. Berlin's edema may look similar clinically but can affect different layers of the retina, possibly depending on the mechanism of injury affecting the eye.

\section{Disclosure}

The authors declare no conflicts of interest in this work. This report received no funding or financial support.

\section{References}

1. Puliafito CA, Hee MR, Lin CP, et al. Imaging of macular diseases with optical coherence tomography. Ophthalmology. 1995;102(2):217-229.

2. Berline R. Zur. Sogenannten commotio retinae. [So-called commotio retinae]. Klin Monatsbl Augenheilkd. 1873;1:42-78. German.

3. Sipperley JO, Quigley HA, Gass DM. Traumatic retinopathy in primates. The explanation of commotio retinae. Arch Ophthalmol. 1978; 96(12):2267-2273

4. Liem AT, Keunen JE, van Norren D. Reversible cone photoreceptor injury in commotion retinae of the macula. Retina. 1995;15(1):58-61.

5. Mansour AM, Green WR, Hogge C. Histopathology of commotio retinae. Retina. 1992;12(1):24-28.

6. Meyer CH, Rodrigues EB, Mennel S. Acute commotio retinae determined by cross-sectional optical coherence tomography. Eur $J$ Ophthalmol. 2003;13(9-10):816-818.

7. Sony P, Venkatesh P, Gadaginamath S, Garg SP. Optical coherence tomography findings in commotio retina. Clin Experiment Ophthalmol. 2006;34(6):621-623.

8. Ismail R, Tanner V, Williamson TH. Optical coherence tomography imaging of severe commotio retinae and associated macular hole. Br J Ophthalmol. 2002;86(4):473-474.

9. Pham TQ, Chua B, Gorbatov M, Mitchell P. Optical coherence tomography findings of acute traumatic maculopathy following motor vehicle accident. Am J Ophthalmol. 2007;143(2):348-350.

10. El Matri L, Chebil A, Kort F, Bouraoui R, Largueche L, Mghaieth F. Optical coherence tomographic findings in Berlin's edema. J Ophthalmic Vis Res. 2010;5(2):127-129.

11. Itakura H, Kishi S. Restored photoreceptor outer segment in commotio retinae. Ophthalmic Surg Lasers Imaging. 2011;42:e29-e31.
Clinical Ophthalmology

\section{Publish your work in this journal}

Clinical Ophthalmology is an international, peer-reviewed journal covering all subspecialties within ophthalmology. Key topics include: Optometry; Visual science; Pharmacology and drug therapy in eye diseases; Basic Sciences; Primary and Secondary eye care; Patient Safety and Quality of Care Improvements. This journal is indexed on

Submit your manuscript here: http://www.dovepress.com/clinical-ophthalmology-journal

\section{Dovepress}

PubMed Central and CAS, and is the official journal of The Society of Clinical Ophthalmology (SCO). The manuscript management system is completely online and includes a very quick and fair peer-review system, which is all easy to use. Visit http://www.dovepress.com/ testimonials.php to read real quotes from published authors. 